\title{
Drag characterisation of prawn-trawl bodies
}

\author{
Cheslav Balash ${ }^{1 \dagger}$, David Sterling ${ }^{2}$, Jonathan Binns ${ }^{1}$, Giles Thomas $^{3}$, Neil Bose ${ }^{1}$ \\ ${ }^{1}$ Australian Maritime College, University of Tasmania, Launceston, Australia \\ ${ }^{2}$ Sterling Trawl Gear Services, Manly, QLD, Australia \\ ${ }^{3}$ University College London, London, UK
}

$\dagger$ Corresponding author

cheslavbalash@yahoo.ca

\begin{abstract}
The drag of a prawn-trawl body is characterised by five design and three operational variables. The design variables comprise headline length, steepness of trawl side cut, width-to-depth mesh ratio of the trawl mouth (gape), vertical wingend mesh count, and netting solidity; all of which effectively determine the planar twine-area of the trawl. The operational variables include towing velocity, horizontal spread, and vertical opening (headline height) - these determine the extent that the netting is exposed to relative water movement. The individual drag effects of the above variables (except for headline length, gape, and netting solidity) were systematically examined in a flume tank with prawn-trawl models built with low-stiffness full-scale netting; and the existing literature was consulted on the drag effects of gape, while drag was assumed to be proportional to twine diameter, mesh size ${ }^{-1}$ and headline length ${ }^{2}$. The developed equations in non-dimensional forms provide the basis for a drag-prediction model for a prawn trawl of any size, construction and operating conditions. Comparisons with previously published prediction equations showed considerable disagreement in some aspects, and suggest that using stiff, full-scale netting in past model experiments have produced significant modelto-full-scale prediction errors owing to the poor equivalence of twine bending-stiffness-to-netting-tension ratio.
\end{abstract}

Keywords: netting drag; trawl body taper; trawl horizontal spread; trawl gape; trawl vertical opening; wing-end mesh count

\section{Introduction}

A prawn-trawling system primarily comprises a funnel-shaped net (trawl) with top and bottom panels (and sometimes side panels), a codend, otter boards, and ground gear. The otter boards provide a desired horizontal opening of the trawl and are connected to the trawl by wires (sweeps), and also to the trawler by bridles and warps to transfer the tow force to the gear (Fig. 1). The ground gear is attached to the front of the bottom panel of the trawl to provide seabed contact, and stimulate prawns to move from the seabed and into the body as trawling occurs. The ground gear allows the trawl's bottom panel to remain clear of the seabed, which minimises netting damage and the catch of seabed objects, including sessile benthic animals.

Trawling systems of this general type are used by approximately 550 trawlers around the Australian coastline to target prawns, and many thousands of trawlers $(5-30 \mathrm{~m}$ in length) throughout the rest of the world. The cost of fuel used to drive these active fishing systems is a large production cost to the industry and a substantial contribution to the carbon footprint of the associated seafood production Parker et al. (2015). For these reasons, there is a great motivation to quantify the drag characteristics and reduce the towing resistance of prawn-trawling systems. 


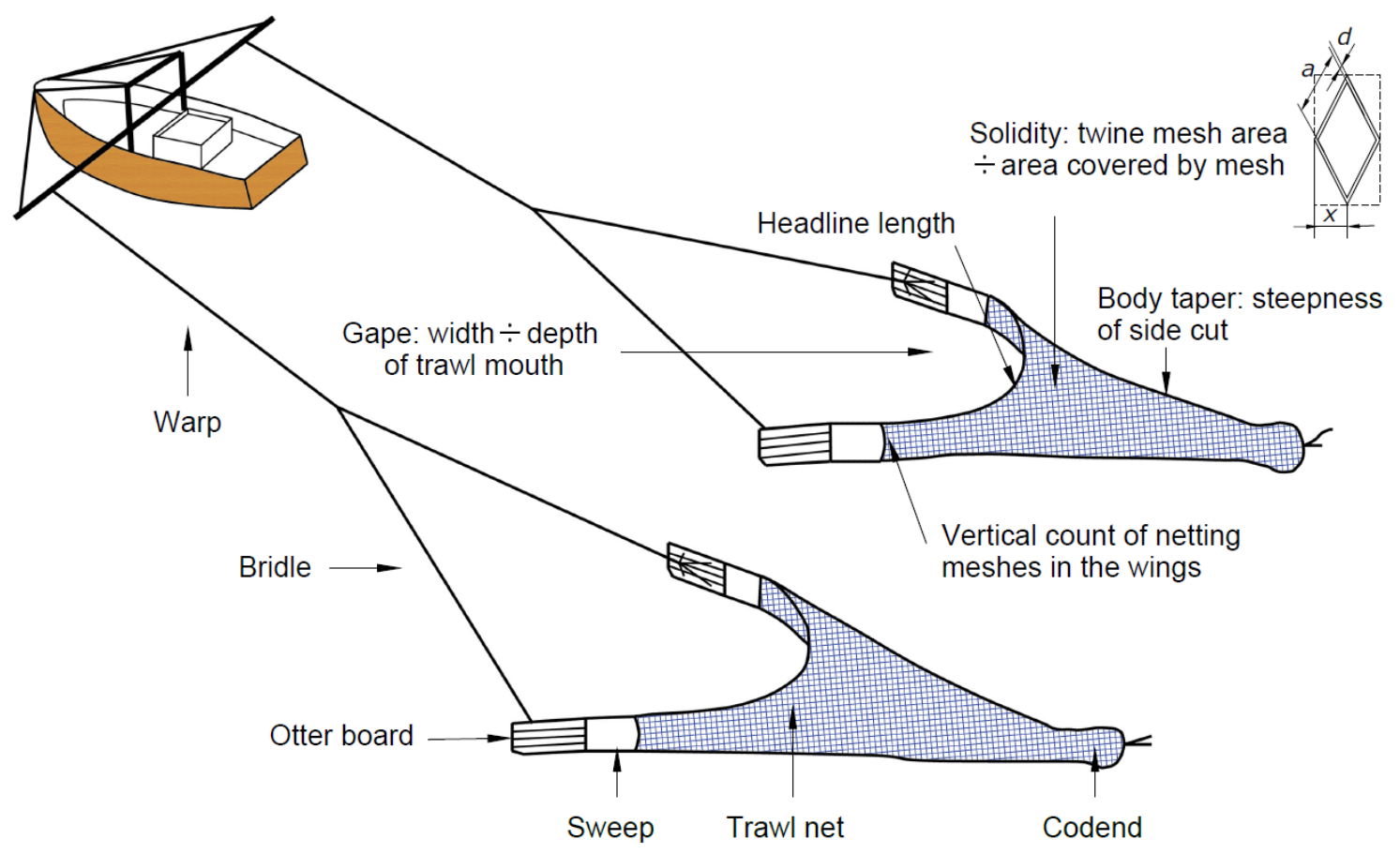

Fig. 1. General arrangement of prawn-trawling system and design parameters of the netting part.

The total netting drag of a trawl can be assumed to be the combined drag of the simple net-panel components. However, the shape and incident angle of the individual panels are not easily determined for a given trawl (Reid 1977). Some researchers have developed drag-prediction equations for particular trawl designs and components based on regression analysis of experimental test results. For example, Ferro \& Stewart (1987) proposed an empirical formula for cod-end drag as a function of cod-end dimensions and mesh size, and Reid (1977) generalised the drag for simple nylon pelagic trawls as a function of towing velocity and twine area, while Sterling (2005) described a comprehensive performance prediction tool for low-opening prawn-trawling systems (Prawn Trawl Performance Model; PTPM ver3), which includes trawl and otter board drag, and seabed-contact forces from the ground gear and otter boards. Sterling's (2005) model is based on core empirical equations characterising the drag of the component trawls as a function of the values of key defining variables readily recorded in trawl plans by net makers and trawl operators. Since its inception, the PTPM ver3 continues to be extensively used for fisheries research and management, and especially as a tool for trawl-system design and assessing the fishing power of operators in key Australian prawn fisheries. More recently, Priour (2009) proposed a finite element analysis method to optimise the netting part of bottom and pelagic trawls with respect to minimum drag and maximum frontal area of the trawl opening by varying the geometry of netting panels.

Following Sterling's (2005) approach, the drag of the netting part of prawn trawls can be characterised by five design and three operational variables. The variables that effectively determine the planar twine-area in the trawl and consequently affect drag are: headline length, body taper (steepness of side cut), gape (width-to-depth mesh ratio of the trawl mouth), vertical wing-end mesh count, and netting solidity (mesh twine area divided by the area covered by mesh); which is a function of mesh size (2a), twine diameter $(d)$ and hanging ratio $(E=x / a)$ (Fig. 1), and a knot factor for knotted netting. The operational variables that affect drag include towing velocity, horizontal spread, and vertical opening (headline height) - these determine the extent the netting is exposed to relative water movement. Sterling (2005) assumed drag is proportional to headline length ${ }^{2}$, velocity ${ }^{2}$, twine diameter and mesh-size ${ }^{-1}$ for geometrically similar trawls; while for the other variables, empirical relationships with drag were developed based on physical-model testing in Australia's flume tank during the 1990s.

Wakeford (1997) conducted flume tank tests on a systematic series of prawn-trawl models of constant length to estimate the effects of gape on swept-area performance, where gape determined the general character of the frame-line tapers and was the ratio of the number of meshes between the wing-ends to the mesh-depth of the trawl mouth. Subsequently, based on Wakeford's (1997) data, Sterling (2005) developed a linear prediction-equation for the effect of gape on drag for trawls that had a constant body taper (trawl length varies with gape value) (Eq. 1):

$$
\text { Drag factor (rel. to } 1.53 \text { gape })=1+0.3869(\text { gape }-1.53)
$$

Balash et al. (2015) demonstrated from flume tank tests that mesh orientation (T0 vs. T45; or 'diamond' vs. 'square') did not have practical drag implications for a prawn trawl; while Broadhurst et al. (2015) found no engineering differences in 
the field between trawls that had T0 or T45 in their side sections, although improved targeted-prawn selectivity was identified for the T45 trawl. Broadhurst et al. (2012) evaluated the engineering and catch performances of prawn trawls with steep or shallow body tapers (1N2B and 1N5B respectively); each with two or four panels. All four treatments were spread with the same steel rectangular otter boards and both 1N5B designs had 4.7-5.6\% more horizontal spread than the longer trawls, while the 1N5B two-panel had 4.3\% less drag than the 1N2B four-panel trawl. Field experiments by Broadhurst et al. (2014) using a prawn trawl connected to a length-adjustable beam (rather than otter boards) revealed a $16 \%$ reduction in total system drag when the trawl's horizontal spread ratio ( $S R$; defined as distance between wing-ends $\div$ the total headline length) was 0.5 rather than 0.8 . Another key drag variable, solidity, determines the amount of twine area contained in a given area of netting. Theoretically the drag force on a screen is proportional to solidity when an assumption of free flow past the twines is made (Fridman 1973). The effects of solidity on netting-sheet drag in quasistatic flow have been quantified by several authors and was reviewed by Tsukrov et al. (2011), revealing significant variation of plane netting drag as a function of solidity. These variations could be due to various factors such as the roughness and flexibility of the twine Tsukrov et al. (2011). To capture all the influences of trawl-design variables on drag, there is continuing value in using controlled model experiments.

The present work assessed individual drag effects due to principal specifications of the netting plan; specifically, nettingdrag measurements were taken in a flume-tank environment for models of a generic prawn trawl with varied body taper, vertical wing-end mesh count, and headline height over a range of horizontal spreads and flow velocities. This data set is an independent replication of that collected during 1990-3 from the same flume tank for the performance prediction tool (PTPM ver3) given in Sterling (2005). Given that the equipment and methodology for measuring trawl drag at the Australian Maritime College flume tank is now more advanced than in the 1990s, there is significant value in confirming/improving the empirical formulae currently employed in the PTPM.

\section{Methods}

Experiments were conducted in the flume tank at the Australian Maritime College, Beauty Point, Tasmania, Australia. The test section of the flume tank is $11.2 \mathrm{~m}$ long, $5 \mathrm{~m}$ wide and $2.5 \mathrm{~m}$ deep. A base $1 / 4$-scale 8 -fathom headline length prawn trawl (3.66 m) was used in the drag evaluation (Fig. 2). The design is a generic Florida flyer, commonly used by Australian prawn trawlers. Overall, five models were built with varying body tapers and wing-end meshes (Table 1). The baseline (reference) model was tested for three different headline heights: low (175 mm), medium (225 mm) and high $(275 \mathrm{~mm})$; while the vertical height was kept constant (at the medium setting) for the other models. All models and height settings were tested at $S R s$ of $0.7,0.8$ and 0.9 and flow velocities of 1.0, 1.2, 1.4 and $1.6 \mathrm{~m} \mathrm{~s}^{-1}$. The reference model was also tested over a wider range of $S R s$ from 0.65 to 0.95 , with 0.05 increments.

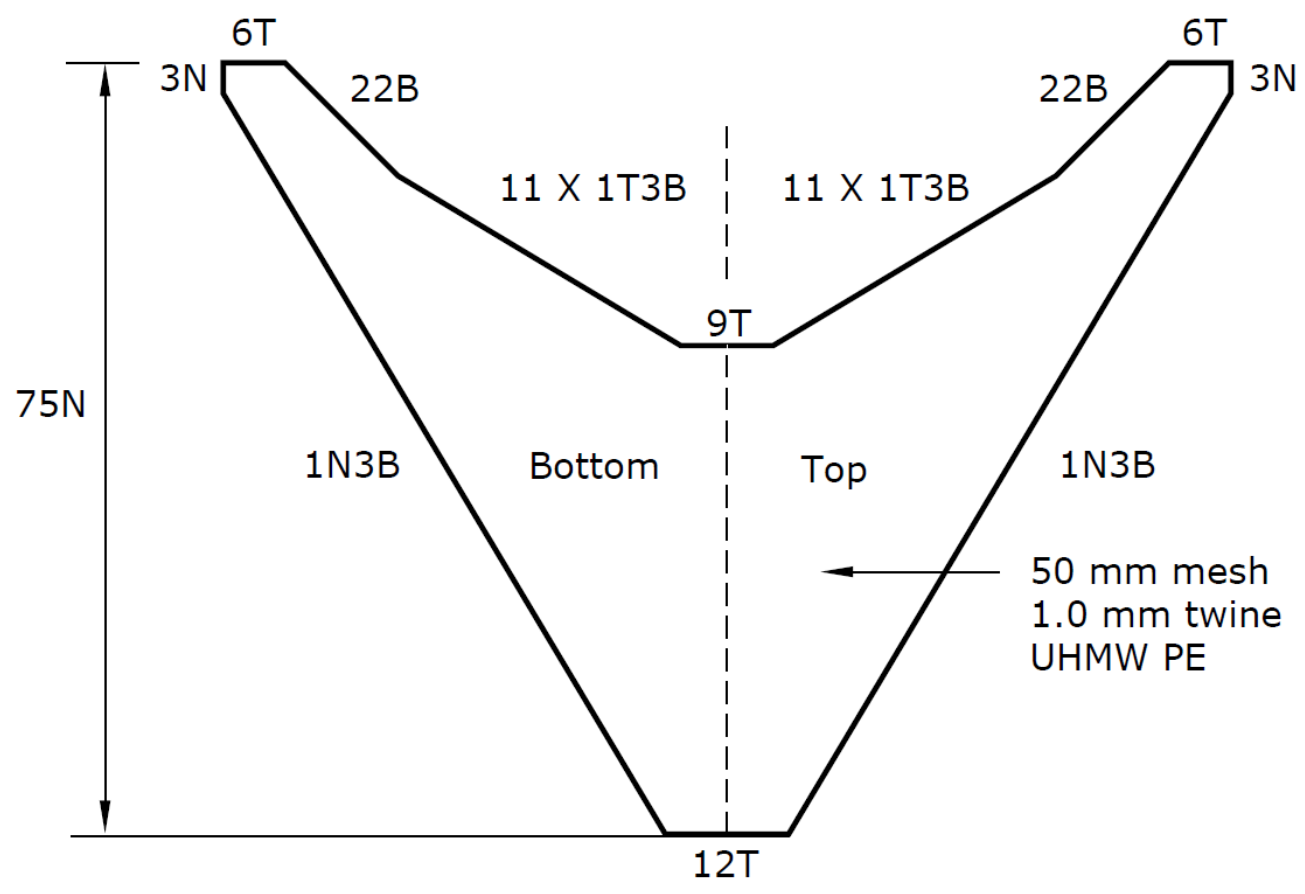

Fig. 2. Net plan for simple 1/4-scale 8-fathom prawn trawl $(3.66 \mathrm{~m})$. 
Table 1. Testing matrix for drag characterisation.

\begin{tabular}{|c|c|c|c|c|c|}
\hline $\begin{array}{l}\text { Model } \\
\text { no. }\end{array}$ & $\begin{array}{l}\text { Body } \\
\text { taper }\end{array}$ & $\begin{array}{l}\text { Vertical wing } \\
\text { mesh count } \\
N_{\text {wing }} \\
\end{array}$ & $\begin{array}{l}\text { Headline } \\
\text { height } \\
H H[\mathrm{~mm}]\end{array}$ & $\begin{array}{l}\text { Spread ratio } \\
S R[-]\end{array}$ & $\begin{array}{l}\text { Flow velocity } \\
{\left[\mathrm{m} \mathrm{s}^{-1}\right]}\end{array}$ \\
\hline 1 & $1 \mathrm{~N} 3 \mathrm{~B}$ & 12 & 225 & $\begin{array}{l}0.65,0.7, \quad 0.75 \\
0.8,0.85,0.9 \text { and } \\
0.95\end{array}$ & \multirow{7}{*}{$\begin{array}{l}1.0,1.2,1.4, \\
\text { and } 1.6\end{array}$} \\
\hline 2 & $1 \mathrm{~N} 2 \mathrm{~B}$ & 12 & 225 & \multirow{6}{*}{$0.7,0.8$ and 0.9} & \\
\hline 3 & $1 \mathrm{~N} 4 \mathrm{~B}$ & 12 & 225 & & \\
\hline 4 & $1 \mathrm{~N} 3 \mathrm{~B}$ & 6 & 225 & & \\
\hline 5 & 1N3B & 18 & 225 & & \\
\hline 1 & 1N3B & 12 & 175 & & \\
\hline 1 & $1 \mathrm{~N} 3 \mathrm{~B}$ & 12 & 275 & & \\
\hline
\end{tabular}

All models were built from nominal 50-mm mesh (centre knot-to-knot), 1.0-mm twine diameter Ultracross Dyneema@ (ultra-high molecular weight polyethylene; UHMW PE); a high-strength low-bending-stiffness material that is used for full-scale prawn-trawl construction and can be advantageously used in model experimentation for the following reasons: (1) use of full-scale material gives a representative Reynolds number (ratio of inertia and viscous forces) when testing at full-scale velocity, and (2) hydrodynamic forces continue to dominate netting mechanical forces at model-scale due to the very low twine-bending-stiffness of the multifilament material.

During prawn trawling, the horizontal trawl opening is maintained by otter boards and is therefore not precisely fixed. For controlled netting-drag measurements in the flume tank the model trawls were attached by the four end points of the upper and lower frame lines to a trawl evaluation rig (TER) instead of otter boards (Fig. 3). The submerged part of the TER comprises an aluminium rectangular frame where the two vertical sides could slide laterally along upper and lower streamlined beams, and be firmly fixed at any desired spread. Each trawl-connection point contained a load cell so that the frame-line tensions at all connection points were measured for each case. Each load cell had a 40 kgf capacity.

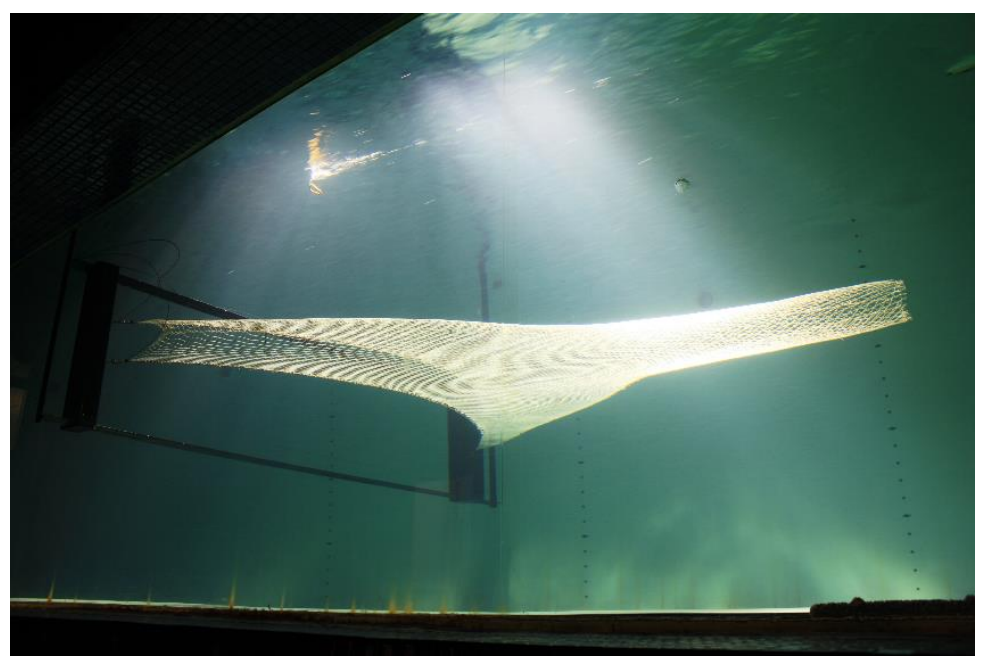

Fig. 3/ Trawl model attached to the Trawl Evaluation Rig (TER) and tested in the mid-stream of the flume tank.

The sum of the two measured tensions for each wing-end, $T_{s t b}$ (starboard wing tension) and $T_{\text {prt }}$ (port wing tension), comprise vector contributions from the in-pull force of the trawl, $F_{\text {in }}$ (this force must be overcome by the otter boards to maintain the open trawl), and drag force. The sum of the drag components from the combined tensions in each wing is the total drag of the trawl, $F_{d}$. The drag force $F_{d}$ and the in-pull force $F_{\text {in }}$ were derived as shown in Eqs. 2 and 3 , respectively. The angle of the frame lines (at the connection points) relative to the flow direction was measured from an overhead view with a bevel gauge referenced to an unsubmerged beam on the TER that was transverse to the flow direction (Fig. 4).

$$
\begin{gathered}
\mathrm{F}_{\mathrm{d}}=\left(\mathrm{T}_{\mathrm{stb}}+\mathrm{T}_{\mathrm{prt}}\right) \cos \theta \\
\mathrm{F}_{\text {in }}=\left(\left(\mathrm{T}_{\mathrm{stb}}+\mathrm{T}_{\mathrm{prt}}\right) / 2\right) \sin \theta
\end{gathered}
$$


To maintain a fixed vertical height across the span of the trawls, four 3-mm fibre-glass struts were equally postioned along the upper and lower frame lines. The strut lengths were 175, 225 and $275 \mathrm{~mm}$ to suit our treatments of low, medium and high headline height, respectively.

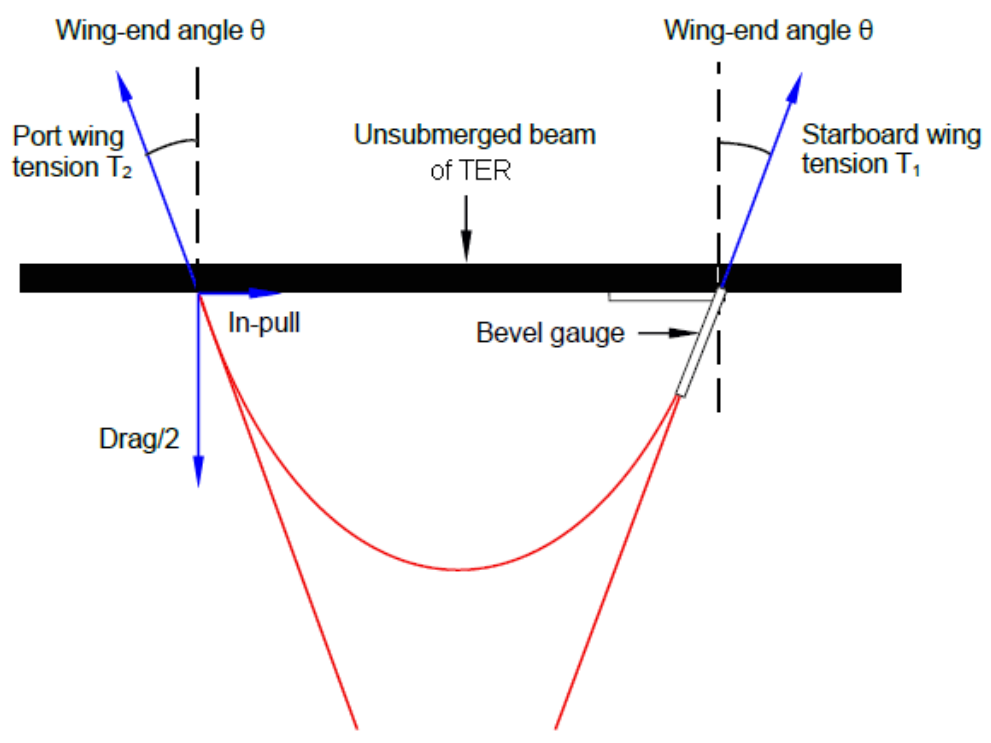

Fig. 4. Schematic of force-vector composition in a prawn trawl and wing-end angle measurement with a bevel gauge.

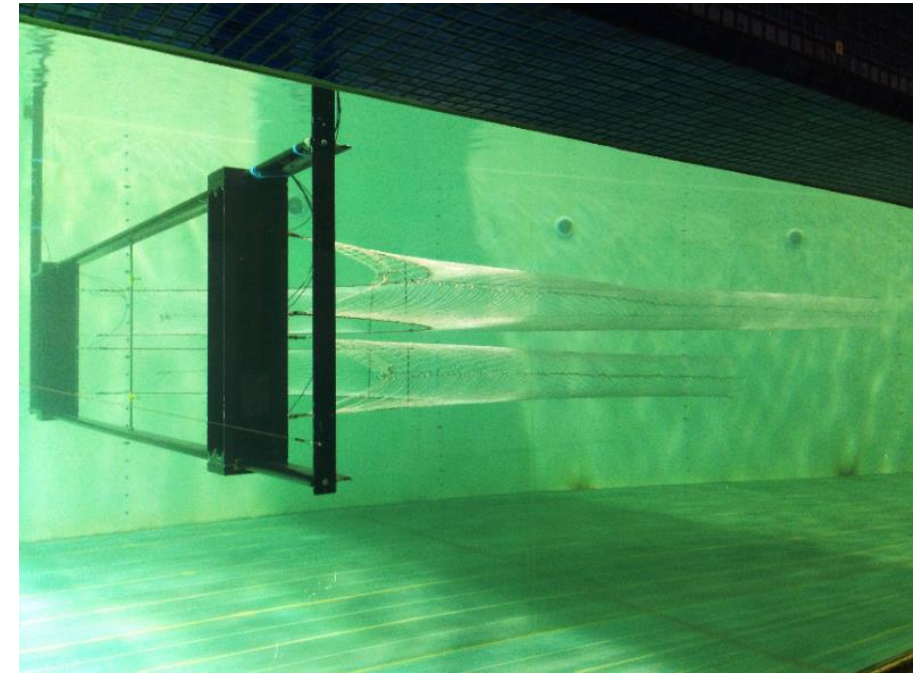

Fig. 5. Paired-comparison of trawl models by streaming simultaneously at the top and bottom of the TER at 0.8 spread ratio; Model 2 with shallow body taper (1N2B) at the top and model 3 with steep body taper (1N4B) at the bottom.

A linear model (LM) of the log-transformed drag data was converged using SPSS (predictive analysis software from IBM) to estimate the multiplicative drag effects of all studied variables (Table 1). For SR, a comparison of estimated means provided a statistical estimate of drag factors (after back-transformation) for each $S R$ with reference to the $0.75 S R$ case. An exponential function was fitted by non-linear, least-squared-error regression to the estimated drag factors to give a realistic prediction equation for interpolation and extrapolation with respect to the data set. Similarly, drag factors were estimated from the LM for the tested wing-end mesh and headline height variables with reference to their medium values. For these variables, non-dimensional scalar equivalents were formed and a two degree-of-freedom relationship was fitted to the results by non-linear, least-squared-error regression. Drag factors were also estimated for the body-taper effect with respect to the $1 \mathrm{~N} 4 \mathrm{~B}$ case.

To check the body-taper results, additional drag measurements were taken for model 2 (1N2B) and 3 (1N4B) whilst positioned simultaniously at the top and bottom of the TER (at 0.8 SR only; Fig. 5). The trawl locations on the TER were then swapped and drag measurements repeated to standardise for location effects (velocity gradients) in the flume tank. A 
LM of the log-transformed data was developed to estimate the effects of trawl position (top vs. bottom), velocity setting in the tank, and trawl type (body taper) on drag-loading of the trawls.

\section{Results}

The estimated drag factors from the LM for each $S R$ with reference to the $0.75 S R$ case were significantly different to the predictive trend provided by Sterling (2005) (Fig. 6). Specifically, Eq. 4 was obtained from least-squared-error regression of the new data and formulates the non-linear dependence, while Eq. 5 is the drag prediction formula from Sterling (2005). The difference manifested as an approximate two-fold rate of drag increase with $S R$ in the new data set.

$$
\begin{aligned}
& \text { Drag factor (rel. to } 0.75)=0.535+0.0567 \mathrm{e}^{2.81 \mathrm{SR}} \\
& \text { Drag factor (rel. to } 0.75)=0.845+0.0099 \mathrm{e}^{3.72 \mathrm{SR}}
\end{aligned}
$$

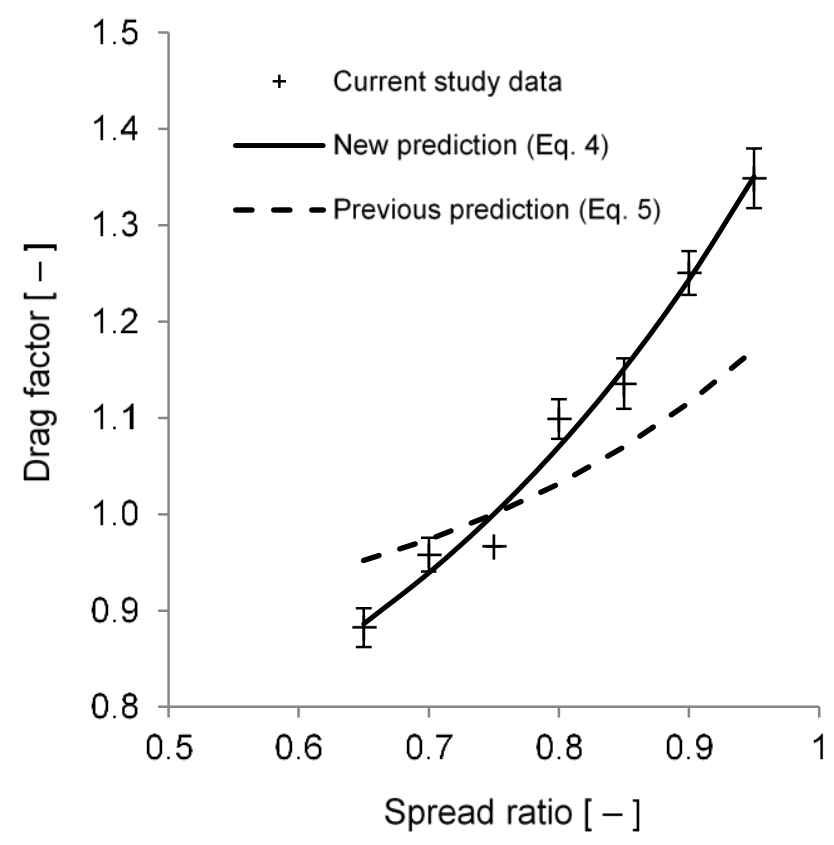

Fig. 6. Drag factor due to horizontal spread with reference to 0.75 spread ratio; current data estimated with $95 \%$ confidence intervals from the LM, new prediction from Eq. 4, previous prediction from Sterling (2005).

Relative drag due to change in vertical wing-end mesh count, with headline height held constant, is presented in Table 2. Vertical count of meshes in the wing-end $\left(N_{\text {wing }}\right)$ is generalised by conversion to the $M R$ (mesh ratio) variable using Eq. 6. $M R$ is the ratio of the vertical length of the wing-end netting at a hanging ratio $E=0.707$, which is when each mesh (of size $l$ ) is stretched to a square, to the headline length $(H L)$-Fig. 1:

$$
M R=\frac{0.707 l N_{\text {wing }}}{H L}
$$

Similarly, headline height $(H H)$ is generalised by conversion to the $M T$ (mesh tautness) variable using Eq. 7:

$$
M T=\frac{H H}{0.707 l N_{\text {wing }}}
$$

$M T$ is the ratio of headline height to the square-mesh vertical length of the wing-end netting.

Relative drag due to any change in the headline height (separation of the upper and lower frame lines), with vertical wing-end mesh count held constant is presented in Table 3.

Eq. 8 formulates the drag-dependence on $M R$ and $M T$ with respect to the case where both variables are set to medium values, and was obtained by least-squared-error regression. The prediction of experimental data based on Eq. 8 and predictions from the equations provided by Sterling (2005) are in general agreement, particularly around the cases tested in the current study (Fig. 7). 


$$
\text { Drag factor }=0.487+2.30 M R e^{1.17 M T}
$$

The drag difference between the $1 \mathrm{~N} 2 \mathrm{~B}$ and $1 \mathrm{~N} 4 \mathrm{~B}$ trawls was $15.1 \pm 1.5 \%$ when tested in the mid-stream one at a time, while the drag result for the $1 \mathrm{~N} 3 \mathrm{~B}$ was closer to $1 \mathrm{~N} 4 \mathrm{~B}$ than $1 \mathrm{~N} 2 \mathrm{~B}$ (Table 4). This closely agreed with the estimated drag difference between $1 \mathrm{~N} 2 \mathrm{~B}$ and 1N4B from the paired comparison of trawls $(14.8 \% \pm 1.2 \%)$, while these results indicate drag is considerably less sensitive to body taper compared to the estimates from Sterling (2005) - Table 4.

Table 2. Estimated relative drag (back-transformed comparison of estimated means) due to vertical wing-end mesh count with $95 \%$ confidence intervals; vertical wing-end mesh count is non-dimensionalised using the MR variable (Eq. 6).

\begin{tabular}{|l|l|l|l|l|}
\hline Setting & $\begin{array}{l}\text { Vertical wing-end } \\
\text { mesh count } \boldsymbol{N}_{\text {wing }}\end{array}$ & $\begin{array}{l}\text { Mesh } \\
\text { tautness } \\
\boldsymbol{M T}[-]\end{array}$ & $\begin{array}{l}\text { Mesh } \\
\text { ratio } \\
\text { MR [ - ] }\end{array}$ & Drag factor [ - ] \\
\hline low & 6 & 1.061 & 0.058 & $0.928 \pm 0.011$ \\
\hline medium & 12 & 0.530 & 0.116 & 1 \\
\hline high & 18 & 0.354 & 0.174 & $1.067 \pm 0.012$ \\
\hline
\end{tabular}

Table 3. Estimated relative drag (back-transformed comparison of estimated means) due to vertical height with 95\% confidence intervals; headline height is non-dimensionalised using the MT variable (Eq. 7).

\begin{tabular}{|l|l|l|l|l|}
\hline Setting & $\begin{array}{l}\text { Headline } \\
\text { height } \\
\boldsymbol{H H}[\mathbf{m m}]\end{array}$ & $\begin{array}{l}\text { Mesh } \\
\text { tautness } \\
\boldsymbol{M T}[-]\end{array}$ & $\begin{array}{l}\text { Mesh } \\
\text { ratio } \\
\boldsymbol{M R}[-]\end{array}$ & Drag factor [ - ] \\
\hline low & 175 & 0.413 & 0.116 & $0.899 \pm 0.010$ \\
\hline medium & 225 & 0.530 & 0.116 & 1 \\
\hline high & 275 & 0.648 & 0.116 & $1.052 \pm 0.012$ \\
\hline
\end{tabular}

Table 4. Estimated relative drag due to body taper with $95 \%$ confidence intervals from the current study and the estimates from Sterling (2005).

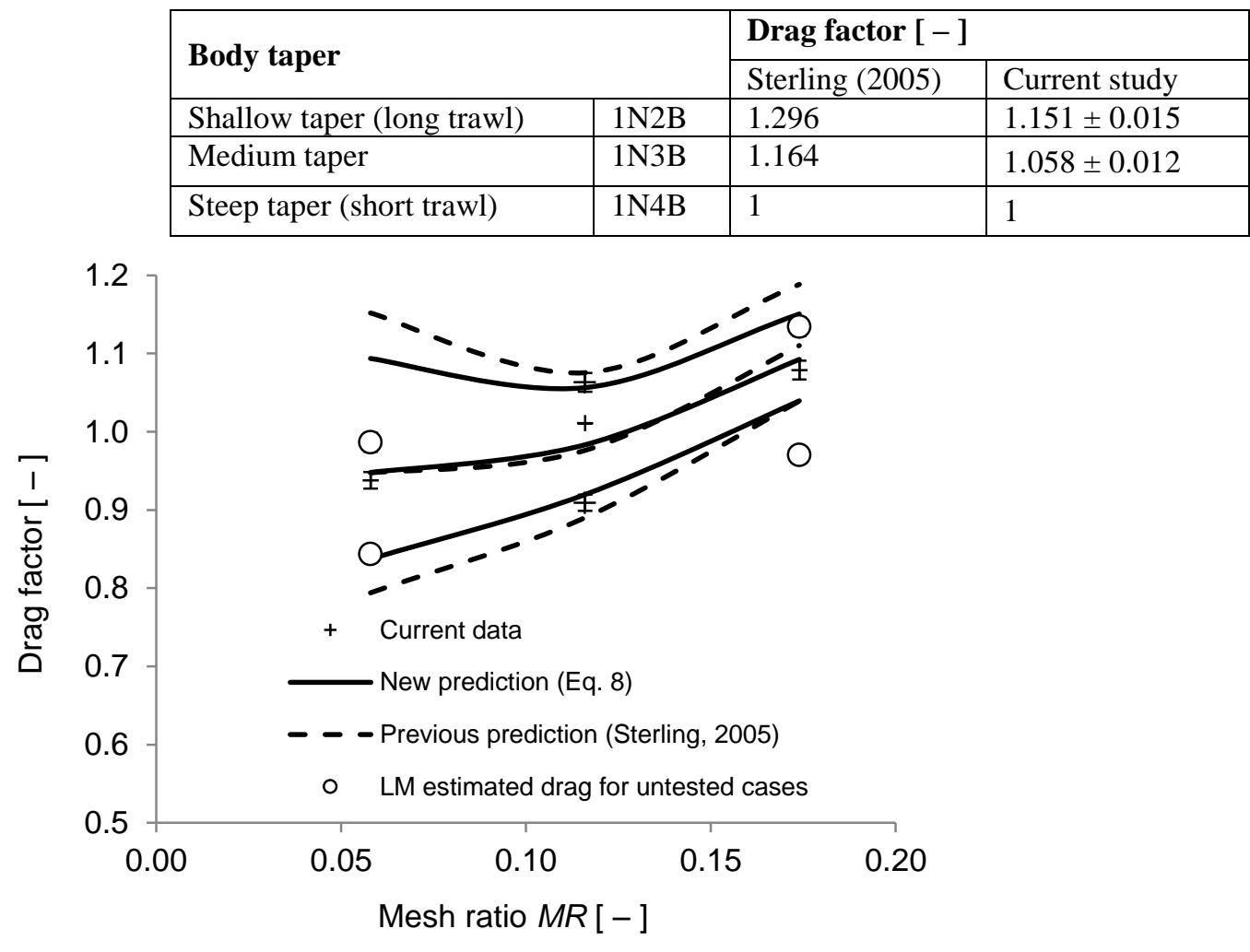

(a) 


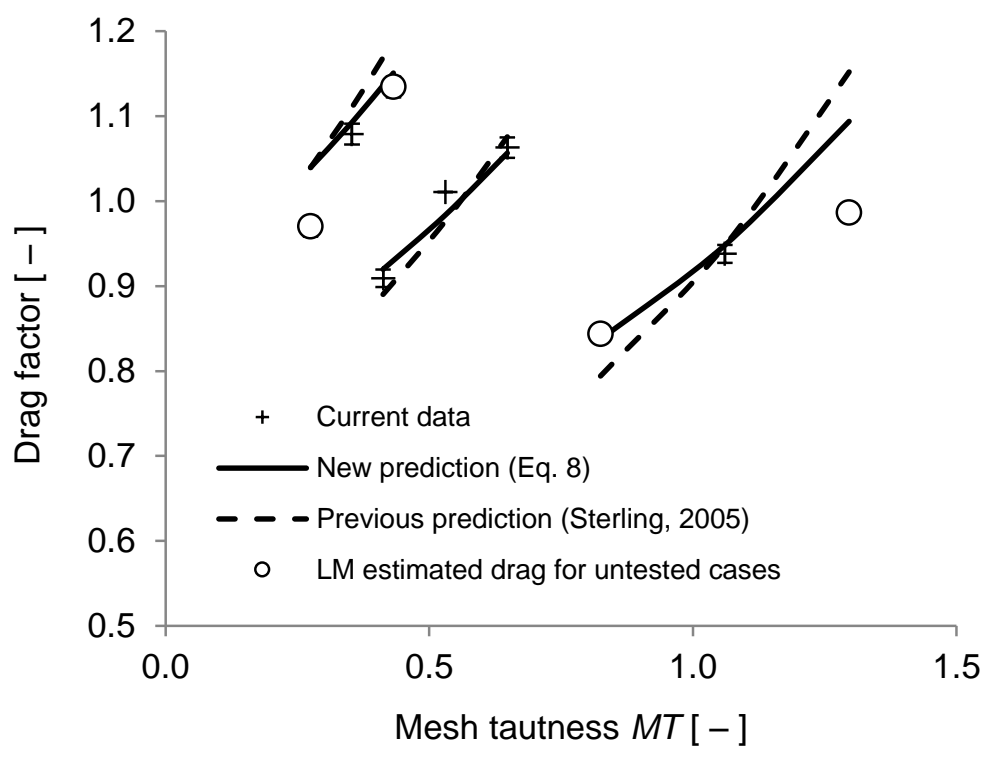

(b)

Fig. 7. Drag factor vs. (a) mesh ratio (MR) with constant headline height groups and (b) mesh tautness (MT) with constant wing-mesh groups; current data estimated with $95 \%$ confidence intervals from the LM for tested cases, new prediction based on Eq. 8, previous prediction from Sterling (2005), and LM predicted drag factors for untested cases.

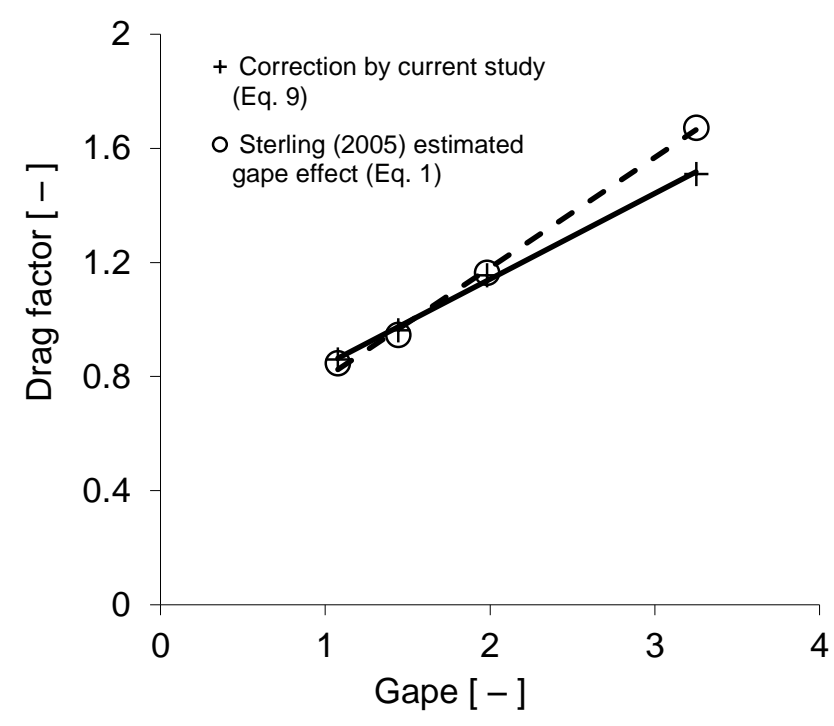

Fig. 8. Drag factor vs. gape; prediction from Sterling (2005) and corrected prediction from the current study based on the new body-taper drag factors.

\section{Discussion}

The collected data showed that body taper, vertical wing-end mesh count, horizontal spread, and headline height have pronounced effects on netting drag. When the $S R$ increased from 0.65 to 0.95 , drag increased by a factor of $1.524 \pm$ 0.034. This result indicates that drag is more sensitive to $S R$ than suggested by Sterling (2005), where the comparable drag factor was 1.230 .

It is possible that the discrepancy between the two data sets was caused by different netting materials. Sterling (2005) used stiff 1.45-mm $\varnothing \mathrm{PE}$ netting, where the twine elements can resist the small bending loads caused by the 
hydrodynamic shaping forces acting on the model trawls. In contrast, the low-stiffness $1.0 \mathrm{~mm} \varnothing$ UHMW PE multifilament netting used in the current study cannot resist bending load and is readily shaped by the flow. It is presumed that the less-stressed shape adopted by the softer netting could result in lower drag. The difference in shape is possibly a particular issue at low $S R$, when the trawl can have relatively large areas of low-tension netting. This characteristic would cause the drag measurements for the current study to be lower for low $S R$ cases and therefore rise more substantially with $S R$ than the stiff netting models from Sterling (2005). Furthermore, the relative drag from testing a small prawn trawl made from semi-stiff netting (Hampidjan Dynex, UHMW PE with a monofilament stiff core) in the flume tank (Balash, Sterling et al. 2015) also showed an increase in the drag across the tested SR range from 0.7 to 0.9 (by a factor of 1.240 ), which is less pronounced than for the current experiment with low-stiffness netting (equivalent drag factor of 1.324) and more pronounced than the result for the very stiff netting used by Sterling (2005) (drag factor of only 1.146). Lastly, the gape data from Wakeford (1997), where stiff netting was used, showed that greater drag at low SRs was more prevalent for high-gape models because there was more loose netting in these trawls over a wider range of low $S R$. The loose netting was prone to transverse oscillation in severe cases (that were excluded from the gape analyses) causing additional drag as described by Johnson \& Balash (2015). The effect of twine stiffness on drag suggested by the model testing would not be apparent in full-scale commercial trawls due to the much greater netting tensions involved. For this reason the drag results of the current study are regarded as more realistic.

The new prediction model for $M R$ and $M T$ produced similar results as Sterling (2005). This is particularly so around the cases tested in the current work. The LM was also used to predict drag factors for the cases that were not tested (high and low headline heights for both high and low wing-end mesh counts). These are plotted in Fig. 8, but were not used to guide the fitting of the $M R-M T$ relationship to the experimental data. For this reason, a comparison of predictions from the LM and the empirical equations for these cases shows how linear extrapolations from the LM compare to the nonlinear extrapolations from the prediction equations. In all four of these cases the new prediction equation gives results closer to the LM predictions than predictions from Sterling (2005). In two cases (low HH, high mesh-number and particularly high $H H$, low mesh-number) there is substantial departure between the two predictions; however, this may not be of any practical concern because they relate to combinations that are not intrinsically used.

A shallower body taper and for this reason inherently longer trawl (1N2B) exhibited a greater drag (by a factor 1.151) than a steep taper and shorter trawl (1N4B). Overall, the drag increase for the 1N2B trawl can be explained by the additional twine area despite the netting in the side sections being inherently exposed to the flow at a lower angle, while the reduced twine area of the 1N4B counteracted a greater angle of exposure to the flow. The data from Sterling (2005) indicated a much greater drag factor of 1.296 between the 1N2B and the 1N4B trawls. Potentially the difference in twine stiffness between the two experiments could have again contributed to the observed differences. The longer 1N2B trawl contains netting that is generally less exposed to the water flow, which would increase the opportunity for stiff netting to adopt a different shape to low-stiffness netting in the same trawl and hence produce a greater drag factor. The potential exists for numerical modelling to further confirm the extent that body taper affects trawl drag and explore the role of twine stiffness at model scale to affect associated empirical data, such as the approach adopted by Zhao et al. (2013) and Bi et al. (2014).

The drag formula due to gape (Eq. 1) developed by Sterling (2005) from flume tank data involved applying drag corrections for the confounding effect of body taper. Given that the estimated drag-effect of body taper has been found to be less substantial, the formulation can be updated to give Eq. 9; with comparison of the two results presented in Fig. 8:

$$
\text { Drag factor (rel. to } 1.53 \text { gape) }=1+0.3006 \text { (gape }-1.53)
$$

However, it could be argued that the estimated effect of body taper by Sterling (2005) might be a better assumption and valid for estimating the drag effect of body taper for the model trawls (1.45 mm PE netting) used by Wakeford (1997), in which case Eq. 1 could still be the more appropriate gape correction for drag. This follows the notion that the lowstiffness material used in the current study gives a better representation of full-scale drag effects, but would not provide the best correction for the transformation of Wakeford's (1997) data set. Further development of the gape-drag relationship would best involve the analysis of additional drag data from low-stiffness model trawls with fixed body tapers and a systematic variation in gape. A numerical drag model of these variant netting structures could also be developed and might become a validated tool for interpolation and extrapolation of drag predictions.

\section{Conclusions}

The effects of key netting-drag parameters of a conventional prawn trawl were assessed, namely: body taper, vertical wing-end mesh count; horizontal spread; and headline height. The findings were that prawn-netting drag increased by factors of (i) $1.151 \pm 0.015$ when the body taper changed from steep (1N4B) to shallow (1N2B); (ii) $1.150 \pm 0.015$ when vertical wing-end mesh count was tripled; (iii) $1.524 \pm 0.034$ when $S R$ changed from 0.65 to 0.95 ; and (iv) $1.169 \pm 0.015$ when headline height changed from low to high ( $41 \%$ to $65 \%$ of the square wing-end mesh height). 
Body taper had a less sensitive drag effect compared to the previous assumptions of Sterling (2005); while the SR drageffect is much more pronounced based on the new data. It is proposed that the modification of predictions is driven by errors associated with using stiff full-scale netting in the original flume tank work, and this was manifested by the ratio of netting tension to twine bending stiffness being well below that occurring in the field.

The developed drag prediction equations for non-dimensionalised variables and drag factors for the categorical variable (body taper) provide the basis for a modified drag prediction model for the entire prawn-trawling system. This represents relatively substantial changes to future predictions of drag and relative performance of different prawn-trawling systems. Future work should involve (i) experimental modelling with low-stiffness netting to update the equation for the drag effect of gape and (ii) numerical modelling to confirm the effect of body taper and gape on drag, and possible interaction effects for the studied variables.

\section{Acknowledgements}

The presented work was funded by the Fisheries Research Development Corporation on the behalf of the Australian Government (Project no. 2011/209).

\section{References}

Balash, C., D. Sterling, J. Binns, G. Thomas and N. Bose (2015). "The effect of mesh orientation on netting drag and its application to innovative prawn trawl design." Fisheries Research 164(0): 206-213.

Balash, C., D. Sterling, J. Binns, G. Thomas and N. Bose (2015). "The 'W' prawn-trawl with emphasised drag-force transfer to its centre line to reduce overall system drag." PLoS One 10(3).

Bi, C. W., Y. P. Zhao, G. H. Dong, T. J. Xu and F. K. Gui (2014). "Numerical simulation of the interaction between flow and flexible nets." Journal of Fluids and Structures 45: 180-201.

Broadhurst, M. K., D. J. Sterling and R. B. Millar (2012). "Short vs long penaeid trawls: Effects of side taper on engineering and catching performances." Fisheries Research 134-136(0): 73-81.

Broadhurst, M. K., D. J. Sterling and R. B. Millar (2014). "Engineering and catch implications of variable wing-end spread on a penaeid trawl." Fisheries Research 153(0): 24-30.

Broadhurst, M. K., D. J. Sterling and R. B. Millar (2015). "Increasing lateral mesh openings in penaeid trawls to improve selection and reduce drag." Fisheries Research 170: 68-75.

Ferro, R. S. T. and P. A. M. Stewart (1987). "The drag of nylon codends." Fisheries Research 5: 331-347.

Fridman, A. L. (1973). Theory and design of commercial fishing gear. Jerusalem, Israel Program for Scientific Translations, $489 \mathrm{pp}$.

Johnson, A. and C. Balash (2015). "Experimental modelling of transverse oscillations in aquaculture netting parallel to the flow - Sounds baffling." Journal of China Ocean Engineering 29(3): 391-400.

Parker, R. W. R., K. Hartmann, B. S. Green, C. Gardner and R. A. Watson (2015). "Environmental and economic dimensions of fuel use in Australian fisheries." Journal of Cleaner Production 87(0): 78-86.

Priour, D. (2009). "Numerical optimisation of trawls design to improve their energy efficiency." Fisheries Research 98(1-3): 40-50.

Reid, A. (1977). "A net drag formula for pelagic nets " Scotish Fisheries Research Report 7.

Sterling, D. (2005). Modelling the physics of prawn trawling for fisheries management ( $\mathrm{PhD}$ thesis), Curtin University of Technology, Perth, 236 pp.

Tsukrov, I., A. Drach, J. DeCew, M. Robinson Swift and B. Celikkol (2011). "Characterization of geometry and normal drag coefficients of copper nets." Ocean Engineering 38(17-18): 1979-1988.

Wakeford, J. (1997). The effect of frameline tapers on the engineering perfomance of prawn trawl systems. Asia-Pacific Fishing. Cairns, Australia.

Zhao, Y. P., C. W. Bi, G. H. Dong, F. K. Gui, Y. Cui, C. T. Guan and T. J. Xu (2013). "Numerical simulation of the flow around fishing plane nets using the porous media model." Ocean Engineering 62: 25-37. 